\title{
Produção da agricultura familiar e participação em mercados locais e institucionais em Cristina (MG)
}

Family farming production and participation in local and institutional markets in Cristina (MG)

\author{
Tayrine Parreira Brito ${ }^{1}$ \\ Samanta Borges Pereira ${ }^{2}$ \\ Viviane Guimarães Pereira ${ }^{3}$
}

\begin{abstract}
Resumo
O objetivo deste artigo foi conhecer a diversidade produtiva e a participação nos mercados locais e institucionais da agricultura familiar de Cristina (MG). Para tanto, foram levantados e analisados os dados do Censo Agropecuário 2006, entrevistas com os técnicos da Emater, entrevista com a feirante agricultora e observação da feira. Os resultados apontaram para uma concentração na produção do café, a descaracterização da feira como espaço de trocas comerciais, culturais e sociais, e participação pequena, mas constante, de famílias agricultoras em programas institucionais. Por meio de incentivos e apoio dos agentes de desenvolvimento local, mais famílias poderiam ser beneficiadas e incluídas tanto na feira livre quanto no PNAE.
\end{abstract}

Palavras-chave: Agricultura familiar. Mercados institucionais. Feira livre. Desenvolvimento rural.

\begin{abstract}
The objective of this article was to know the local and institutional market's productive diversity and family farming participation in the municipality of Cristina (MG). For that purpose, the agricultural Census 2006 data were collected and analyzed, interviews with EMATER's technical technicians from the municipality, an interview with a marketer-farmer and fair observation. The results pointed to a concentration on coffee production, a lack of characterization of the fair, as space for commercial, cultural and social exchanges, and small but constant participation of farming families in institutional programs. Through incentives and support from local development agents, more families could be benefited and included, both at the fair and at the PNAE.
\end{abstract}

Keywords: Family farming. Institutional markets. Free-fair. Rural development.

\footnotetext{
1 Mestre em Desenvolvimento, Tecnologias e Sociedade pela Universidade Federal de Itajubá. E-mail: tairine_prospe@hotmail.com

2 Mestre em Desenvolvimento, Tecnologias e Sociedade pela Universidade Federal de Itajubá. E-mail: samantaborges81@gmail.com

${ }^{3}$ Doutora em Administração. Professora da Universidade Federal de Itajubá. E-mail: vgpereira@ yahoo.com.br
} 


\section{Introdução}

A discussão levantada neste artigo $^{4}$ situa-se no campo da agricultura familiar e do desenvolvimento rural e envolve a diversidade produtiva e a inclusão em mercados que garantam além da comercialização dessa produção, a soberania alimentar, a qualidade de vida, o respeito às suas origens sociais e culturais e a reprodução dos modos de vida das famílias agricultoras.

O município escolhido para realizar esta pesquisa foi Cristina, localizado no sul de Minas Gerais, conhecido pela produção cafeeira. Ainda que tradicional e relevante para a economia da região, a monocultura cafeeira traz para agricultura familiar algumas inseguranças, como a instabilidade desse mercado. Por tratar-se de uma commodity, o preço do café oscila de acordo com o mercado mundial - e a pouca diversidade nos cultivos -, que dificulta a produção para autoconsumo (BARBOSA et al., 2016).

Para Abramovay (1992), a produção da agricultura familiar é uma via para garantir a segurança alimentar das famílias agricultoras, já que caso o mercado não lhes seja adequado, a alimentação das famílias não estará comprometida. A diversificação na produção familiar pode ser uma alternativa para os agricultores aumentarem seus rendimentos e melhorar a qualidade de vida no campo, evitando a dependência de apenas um mercado (BARBOSA et al., 2016).

$\mathrm{O}$ fomento às políticas de mercados institucionais, como o Programa de Aquisição de Alimentos (PAA) e o Programa Nacional de Alimentação Escolar (PNAE) nos últimos anos, e os incentivos aos mercados locais, como as feiras livres e as iniciativas de economia solidária, possibilitaram uma maior abertura para o escoamento da produção da agricultura familiar, valorizando e favorecendo a diversidade produtiva.

Nesse sentido, as perguntas que nortearam este trabalho foram: existe diversidade produtiva na agricultura familiar desse município? Há participação dos agricultores e agricultoras de Cristina nos mercados locais e institucionais? Das perguntas, emergiu nosso objetivo: conhecer a diversidade produtiva e a participação nos mercados locais e institucionais da agricultura familiar do município. Foram levantados e analisados os dados do Censo Agropecuário 2006, realizadas entrevistas com os técnicos da Emater e visita à feira local, entrevistando a única agricultora participante.

A definição conceitual da agricultura familiar pautou-se em Wanderley (2009), Medeiros (2001), Moraes (1998) e Durham (1984). A revisão teórica abordou ainda as políticas públicas para

\footnotetext{
${ }^{4}$ Este artigo foi elaborado a partir do texto intitulado "Mercados locais e institucionais para a agricultura familiar: um relato sobre Cristina - MG" apresentado no II Seminário de Políticas Culturais e Ambientais, realizado em agosto de 2017, na Universidade Federal de Itajubá, em Itajubá (MG), com previsão de publicação nos anais do congresso em 2018.
} 
a agricultura familiar, mais especificamente o Programa Nacional de Alimentação Escolar (PNAE) como estrutura e objetivos. As pesquisas empíricas sobre o desenvolvimento do programa em diversas partes do país serviram de referência para comparação com a realidade de Cristina. As recentes pesquisas de Baccarin et al. (2017), Rossetti, Winnie e Silva (2016), Costa, Amorim Jr. e Silva (2015), Castro (2014), Souza-Esquerdo e Bergamasco (2014), Marques et al. (2014) e Ribeiro, Ceratti e Broch (2013) sobre o tema foram o aporte para a compreensão da realidade pesquisada.

Sobre as feiras livres, foram priorizadas importantes pesquisas como a de Ribeiro (2007) sobre as feiras do Jequitinhonha, e Braudel (2009) sobre as feiras como espaço de confiança, entre outros autores que contribuíram com aspectos mais gerais ou mais específicos referentes à dinâmica da feira.

Os resultados apresentados poderão contribuir com informações relevantes para o poder público, juntamente com as agências de desenvolvimento rural, quanto às medidas de incentivo à diversidade produtiva local, ao fortalecimento da identidade rural e ao fomento aos espaços de comercialização e sociabilização para os agricultores e agricultoras familiares.

\section{Metodologia}

A coleta de dados foi realizada em três vertentes: (i) levantamento dos dados secundários do Censo Agropecuário apresentado pelo Instituto Brasileiro de Geografia e Estatística (IBGE), referente ao ano de 2006; (ii) entrevista com os responsáveis pela Emater; (iii) entrevista com a feirante agricultora juntamente com observações da feira.

Foram levantados os dados do Censo Agropecuário 2006 referentes à área dos estabelecimentos agropecuários (hectares), presença de lavouras e pecuária, número de estabelecimentos agropecuários com agricultura familiar, área dos estabelecimentos agropecuários da agricultura familiar e pessoal ocupado em estabelecimentos com agricultura familiar. As informações estatísticas e suas análises, baseadas nas discussões de Wanderley (2001), ofereceram um panorama geral da agropecuária em Cristina e contribuíram para compreender a relevância da agricultura familiar e do meio rural em municípios de pequeno porte.

A entrevista com os técnicos da Emater ocorreu no dia 14 de outubro de 2016. Foram abordadas questões sobre os principais cultivos, destino da produção, produtos e produtores de referência, presença de produção orgânica/agroecológica, criação animal, participação da Emater na organização produtiva dos agricultores, presença de agroindústrias familiares e comunitárias, 
participação no Programa de Aquisição de Alimentos (PAA) e Programa Nacional de Alimentação Escolar (PNAE).

A pesquisa com a Emater forneceu algumas informações preliminares sobre a feira e a presença de uma feirante agricultora. A visita à feira de Cristina foi realizada no dia 23 de outubro de 2016 e a entrevista com a agricultora, agendada previamente, aconteceu durante a feira. Foram abordadas questões sobre comunidade pertencente, importância da feira na composição da renda familiar, diversidade da produção familiar e o espaço da feira: infraestrutura e apoio do poder público. Além da entrevista, foi realizada observação da feira para quantificação de número de barracas e identificação dos produtos comercializados nesse espaço.

A análise dos dados levantados em campo foi realizada pela interlocução entre a teoria referente aos mercados estudados e agricultura familiar brasileira com a realidade das famílias agricultoras de Cristina.

\section{As políticas públicas para a agricultura familiar: do Pronaf aos mercados institucionais}

Da perspectiva teórico-conceitual, a política pública situa-se no campo multidisciplinar centrada na elucidação sobre a natureza da política pública e seus processos, a partir de teorias advindas da Sociologia, da Ciência Política e da Economia (SOUZA, 2006). Na revisão de literatura realizada por Souza (2006), ela afirma que não existe uma única ou melhor definição sobre política pública e dentre as diversas referências utilizadas pela autora, a mais conhecida é a de Laswell, que sustenta que "decisões e análises sobre política pública implicam responder às seguintes questões: quem ganha o quê, por quê e que diferença faz" (LASWELL, 1936;1958 apud SOUZA, 2006, p. 24).

Contribui com essa definição a compreensão de Höfling (2001), que estabelece que as políticas públicas se referem à implantação de um projeto de governo pelo Estado, através de programas e de ações direcionadas para esferas específicas da sociedade. A autora diferencia Estado de Governo: o primeiro sendo o conjunto de instituições permanentes que possibilitam a ação do governo, e o segundo como o conjunto de programas e projetos propostos para a sociedade desenhando a orientação política de um determinado governo que assume e executa as funções de Estado durante um intervalo de tempo estabelecido (HÖFLING, 2001).

Nesse sentido, a partir dos anos 1990, iniciou-se uma mudança na ação do Estado brasileiro no estímulo ao desenvolvimento rural em novas bases. Nessa nova perspectiva, a agricultura familiar ganhou destaque nas políticas públicas nacionais, quando passaram a ser incorporadas, mesmo que 
parcial e incompleta, as demandas das populações rurais, através de um conjunto de políticas públicas que procuraram garantir seu fortalecimento econômico e social, pautadas na reforma agrária, no crédito para agricultura familiar e no apoio aos territórios rurais.

A categoria agricultura familiar compreende uma grande diversidade de formas sociais, em que estão incluídos o campesinato tradicional e as formas da agricultura familiar nas sociedades modernas, incorporando, assim, toda a população rural que administra um estabelecimento agrícola, gere e trabalha nele com a família, sejam eles assentados, reassentados, agricultores tradicionais, agricultores integrados, arrendatários, posseiros ou meeiros (WANDERLEY, 2009).

Os agricultores se organizam economicamente apoiados em unidades produtivas individuais, mas ao mesmo tempo, se desenvolvem nos limites da comunidade, onde se efetua a sua sociabilidade. Pode-se afirmar que nunca foram completamente isolados e autossuficientes, existindo uma relação de dependência com relação ao mundo exterior que é o fundamento da sua integração na sociedade nacional (DURHAM, 1984).

Há duas características fundamentais para se definir o agricultor familiar: 1) unidades de produção administradas pelas próprias famílias que nelas trabalham diretamente, com ou sem auxílio de terceiros; e 2) gestão das unidades produtivas autônoma, feita pela própria família. A denominação agricultura familiar surgiu como fruto da mobilização dos movimentos sociais a partir dos anos 1990 e está ligada à redemocratização do país e às demandas por políticas específicas (MEDEIROS, 2001; MORAES, 1998).

O conjunto de políticas públicas para a agricultura familiar foi inaugurado pelo Pronaf (Programa Nacional de Fortalecimento da Agricultura Familiar) em 1994, como resultado da articulação e mobilização dos movimentos sociais e dos movimentos sindicais de trabalhadores rurais pela luta por terra e por políticas agrícolas distintas para essa categoria. O programa, a princípio, foi administrado pelo Ministério da Agricultura e posteriormente associado ao Ministério do Desenvolvimento Agrário (MDA), criado em 1999. O Pronaf foi a primeira de uma série de políticas públicas destinadas à agricultura familiar, as quais foram implementadas do final da década de 1990 até o ano de 2016, que reconheceu dentre suas diretrizes a agricultura familiar como uma categoria social (GRISA; SCHNEIDER, 2014).

Após o Pronaf, novas políticas foram construídas, dando seguimento a esse processo de fortalecimento da agricultura familiar: Programa de Aquisição de Alimentos (PAA-2003), Programa de Habitação Rural (PNHR-2003), Programa Desenvolvimento Sustentável de Territórios Rurais (Pronat-2005), Seguro da Agricultura Familiar (Seaf-2004), Programa de Garantia de Preço da Agricultura Familiar (PGPAF-2006), Programa Territórios da Cidadania (PTC-2008), Política de 
Garantia de Preços Mínimos (PGPM-2008), Programa Nacional de Alimentação Escolar (PNAE-2009), Política Nacional de Agroecologia e Produção Orgânica (PNAPO-2012) e o retorno da Assistência Técnica e Extensão Rural (Ater) pública (CARNEIRO, 1997; SCHNEIDER, 2009; GRISA; SCHNEIDER, 2014).

Esse reconhecimento esteve relacionado às lutas sindicais, na retomada dos sindicatos de trabalhadores rurais, nas lutas por créditos, por preços e condições de venda melhores e pela previdência social rural. As lutas deram ênfase a essa categoria já existente, mas até então não reconhecida (SCHNEIDER, 2010). O reconhecimento trouxe para a agricultura familiar a legitimidade, fundamental para se constituir uma alternativa ao modelo agroexportador, diferenciando agricultores familiares de grandes proprietários de terras.

Algumas dessas políticas foram elaboradas especificamente para abordar o escoamento da produção da agricultura familiar, buscando atender uma necessidade histórica por preço justo para sua produção e segurança de mercado, ou seja, produzir sabendo o destino e a quantidade da venda.

Buainain e Souza Filho (2006) constataram que um ponto fundamental para o sucesso do empreendimento rural familiar está no acesso aos mercados que melhor remuneram seus esforços, sejam eles mercados tradicionais e/ou novos. Outros meios de inclusão produtiva para a agricultura familiar, classificados pelo autor como mercados domésticos ou tradicionais, incluem, por exemplo, as feiras livres, "o lócus e meio de inserção de uma parcela significativa dos agricultores familiares nos mercados" (BUAINAIN; SOUZA FILHO, 2006, p. 73), justamente por se proliferarem em todas as cidades.

Para Schneider (2010, p. 09),

[...] a capacidade de inovação dos agricultores familiares e sua interação com as instituições locais são fundamentais para que possam ampliar a geração e agregação de valor, assim como reduzir custos de transação e estimular economias de escopo.

Trata-se de uma produção voltada ao abastecimento local, em que a economia gerada permanece também no local. Esse é um caminho que, a despeito de suas limitações, tem demonstrado resultados efetivos para o desenvolvimento da agricultura familiar. Os governos têm atuado na compra direta de alimentos da agricultura familiar por meio de programas específicos, criando os chamados mercados institucionais (BUAINAIN; SOUZA FILHO, 2006).

Como exemplo, temos o Programa Nacional de Alimentação Escolar (PNAE), um programa com mais de 50 anos de existência que tem por objetivo suprir parcialmente as necessidades nutricionais dos alunos da rede pública de ensino, no intuito de atender os requisitos nutricionais 
referentes ao período em que os estudantes se encontram na escola (FNDE, 2017). Trata-se da assistência financeira suplementar com vistas a garantir no mínimo uma refeição diária aos alunos beneficiários, assunto que será desenvolvido na seção seguinte.

\section{O Programa Nacional de Alimentação Escolar (PNAE)}

Embora o PNAE seja um programa antigo, somente em 2009 a agricultura familiar passou a ser parte da execução dele, ganhando o programa uma nova configuração, que ampliou seus objetivos. Instituído pela Lei $n^{\circ} 11.947 / 2009,30 \%$ do recurso que o Fundo Nacional de Desenvolvimento Educacional (FNDE) encaminha para as secretarias de educação e escolas executarem o PNAE deve ser utilizado na aquisição de alimentos direto da agricultura familiar.

O PNAE é um programa coordenado nacionalmente pelo FNDE, responsável por elaborar as normas, controlar e destinar o recurso e monitorar a execução, sendo este uma autarquia vinculada ao Ministério da Educação (MEC). A implementação do PNAE é incumbência dos setores ligados à educação, tanto dos municípios quanto dos estados. Esses setores são responsáveis por garantir, em conjunto com o FNDE, a execução do PNAE nas escolas que lhes cabem responsabilidade pelo funcionamento, sendo denominados por Entidades Executoras (EEx). As escolas/unidades onde acontece a execução são chamadas de Unidades Executoras (UEx) (BRASIL, 2009).

Como parte da gestão, existe ainda a atuação da sociedade civil, que fiscaliza e controla dentro dos Conselhos de Alimentação Escolar (CAEs) a implementação do PNAE. É dentro desses conselhos que a sociedade acompanha, avalia e faz apontamentos sobre o programa. O CAE pode ser no nível estadual e municipal e é obrigado a emitir relatórios anuais sobre os processos de execução do programa; caso não envie, são geradas implicações para a liberação do recurso do próximo ano (BRASIL, 2009).

O FNDE encaminha para as EEx o recurso suplementar e as prefeituras e os governos estaduais devem arcar com o restante do recurso necessário. A obrigação dos $30 \%$ para aquisição de produtos da agricultura familiar refere-se somente ao recurso suplementar que o FNDE encaminha, não havendo obrigatoriedade sobre a verba do estado e da prefeitura (BRASIL, 2009).

As determinações anuais de valores a serem repassados para cada categoria obedecem ao número de alunos e dias letivos. Os valores diários destinados a cada aluno conforme a categoria são: (1) Programa de Fomento às Escolas de Ensino Médio em Tempo Integral: R\$2,00; (2) Creches: R\$ 1,07; (3) Ensino Integral: R\$ 1,07; (4) Escolas indígenas e quilombolas: R\$ 0,64; (5) Pré-escola: 
$\mathrm{R} \$$ 0,53; (6) Alunos que frequentam o Atendimento Educacional Especializado no contraturno: $\mathrm{R} \$ 0,53$; (7) Ensino fundamental e médio: R \$ 0,36; (8) Educação de jovens e adultos: R \$ 0,32 (FNDE, 2017).

A gestão do PNAE pode ser de duas formas: centralizada, quando estados e municípios ficam responsáveis por fazer toda a gestão do programa; ou descentralizada e escolarizada, quando as escolas ficam responsáveis pela gestão, recebendo diretamente o repasse do recurso pelo FNDE (BRASIL, 2009).

A participação da agricultura familiar acontece por meio das chamadas públicas, que são abertas anual ou semestralmente. Para isso, as famílias interessadas precisam entregar um projeto de venda que contenha os alimentos e a quantidade que a família propõe entregar. Para seleção existem grupos preferenciais que devem ser respeitados, conforme afirmação de Baccarin et al. (2017, p. 02),

[...] a nova legislação do PNAE estabelece que, nas compras, devam ser priorizados públicos específicos, como os assentados da reforma agrária, quilombolas e indígenas, os que produzem de forma orgânica/agroecológica e os organizados em cooperativas ou associações, nesta ordem.

Esse elenco de prioridade cumpre com o papel fundamental de incluir grupos específicos da agricultura familiar que estiveram à margem de outros programas, pois são categorias dentro de um mesmo grupo social que estiveram em situações de maior vulnerabilidade social. Além disso, a primazia desses grupos fomenta a organização entre as famílias, uma vez que associações e cooperativas também estão sendo antepostas.

A participação da agricultura familiar no PNAE foi considerada por estudiosos da área e pelos movimentos sociais e sindicais ligados ao campo um grande ganho, já que esse grupo social tem na comercialização de sua produção um dos maiores gargalos.

Souza-Esquerdo e Bergamasco (2014, p. 14) afirmaram que:

[...] a inserção da agricultura familiar local e/ou regional como fornecedora de alimentos para a alimentação escolar contribuiu para a promoção de uma alimentação mais saudável e para o respeito dos hábitos alimentares baseados no consumo de produtos locais.

Para Ribeiro, Ceratti e Broch (2013), além do PNAE promover o fortalecimento dos agricultores familiares, ele influencia a criação de hábitos alimentares saudáveis e o desenvolvimento local dos municípios brasileiros, legitimando a sustentabilidade. Para as autoras, o programa 
[...] constitui-se em expressivo mercado consumidor de diferentes demandas reprimidas, bens e serviços da economia urbana (gerando emprego e renda) e rural (ao adquirir produtos da agricultura familiar, mantendo o produtor e sua família no campo), permitindo a inclusão tanto de beneficiários como fornecedores, e respeitando culturas, tradições e comportamentos alimentares tão diferenciados (RIBEIRO; CERATTI; BROCH, 2013, p. 47-48).

O PNAE passou por um reajuste orçamentário em 2017 com um aumento de até 20\%, valores repassados para o ensino fundamental e médio (FNDE, 2017). Ainda assim, e apesar do potencial dessa política pública como geração direta de renda aos camponeses, o programa vem sofrendo ataques e cortes no orçamento pelos resultados positivos atingidos (PAULA; GÓMES; TRACZ; 2017), resultado da escalada dos pensamentos neoliberais do atual governo, com cortes em direitos e programas sociais, anúncios de privatizações e redução dos programas para a agricultura camponesa (MATTOS, 2017). Para Mattos, o enfraquecimento e a extinção das políticas públicas para o campo representam:

[...] impactos potenciais que podem recrudescer a violência no campo, impulsionar a retomada do êxodo rural, elevar a vulnerabilidade social e o empobrecimento no meio rural, reduzir a produção de alimentos ao mercado de consumo doméstico e acometer a garantia de segurança alimentar e nutricional da sociedade brasileira (MATTOS, 2017, p. 1).

$\mathrm{Na}$ análise realizada por Mattos (2017) sobre a recente desestruturação das políticas públicas voltadas à agricultura familiar brasileira, o autor aponta que o aumento da dotação atual entre 2016 e 2017 representa uma estratégia para ocultar a oposição do atual governo aos direitos fundamentais estabelecidos pela Constituição de 1988. A execução orçamentária do PNAE, em 2017, via Sistema Integrado de Planejamento e Orçamento (SIOP) mostra que até outubro do ano corrente apenas 53,4\% da dotação havia sido empenhada ou paga. Além disso, pela primeira vez desde que os dados estão publicamente disponíveis (a partir de 2000) uma gestão governamental não irá quitar a Dotação Anual (MATTOS, 2017).

Junte-se a isso a extinção do Ministério de Desenvolvimento Agrário (MDA), responsável pelo suporte e investimentos de recursos na agricultura familiar e que teve, entre outras consequências, a diminuição dos recursos destinados às políticas públicas específicas para essa categoria.

Nesse sentido, é preciso reconhecer que existem ainda muitos desafios para serem superados: 
da luta pela manutenção dos programas de apoio a essa importante categoria à discussão das particularidades e dificuldades de cada política, de modo a abranger a sua atuação e torná-los mais inclusivos.

\section{Feira livre: espaço de trocas sociais e comerciais}

O intenso debate pela necessidade de consolidação e do alcance das políticas públicas aos agricultores familiares inflama a busca por mercados que permitam à família agricultora, além da venda de seu cultivo, contribuir com o desenvolvimento rural, por meio de um ciclo de geração de renda, qualidade de vida, preservação da cultura local, sustentabilidade social e ambiental, além de melhorias nas técnicas e infraestrutura agrícolas.

O interesse no tema sobre a relação entre mercados e a agricultura familiar é recente (SCHNEIDER; FERRARI, 2015). Nesse sentido, discussões acerca dos circuitos curtos de comercialização têm se mostrado uma forma de venda da produção local de alimentos (FERRARI, 2011). Esses mercados emergentes formam-se a partir do âmbito local e do relacionamento direto entre compradores e vendedores na lógica do estabelecimento de cadeias curtas de comercialização (SCHNEIDER; FERRARI, 2015).

Segundo Schneider e Ferrari (2015), as cadeias curtas se apresentam como opções em 03 dimensões: (1) espaciais, ao abreviar as distâncias que os alimentos percorrem entre a produção e o consumo; (2) social, ao gerar contato face a face entre produtores e consumidores, que resultam em confiança e integração na cadeia; e (3) econômica, criando mercados locais para a produção.

Para Ferrari (2011), uma característica relevante das cadeias agroalimentares curtas é a habilidade para ressocializar ou reespacializar o alimento, possibilitando o julgamento de valor pelo consumidor. Segundo o autor, espera-se que os mercados de venda direta possibilitem preços justos, a reconquista do controle sobre as vendas pelo agricultor e a participação do consumidor na avaliação da qualidade dos produtos.

Nesse sentido, as feiras livres apresentam-se como um importante canal de escoamento da produção da agricultura familiar, de relevância irrefutável, onde se apresentam uma verdadeira teia de relações. São espaços públicos e lugares de interação onde diferentes racionalidades, para além da econômica, tais como a comunitária, a religiosa, a familiar e a societária se influenciam mutuamente, com imenso potencial para a reprodução social (ANGULO, 2003; GODOY; ANJOS, 2007; RIBEIRO, 2007; CARPEGEANI; FILHO, 2009). Para Mascarenhas e Dolzani (2008, p. 75), a feira 
livre no Brasil

[...] constitui modalidade de mercado varejista ao ar livre, de periodicidade semanal, organizada como serviço de utilidade pública pela municipalidade e voltada para a distribuição local de gêneros alimentícios e produtos básicos.

A feira promove geração de renda, fortalecimento das relações de confiança e das identidades regionais, além de oferecer produtos reconhecidamente de qualidade e acessíveis à população, contribuindo com a garantia da segurança alimentar, conforme estabelece a Lei nº 11.346/2006, que criou o Sistema Nacional de Segurança Alimentar e Nutricional (SISAN). A segurança alimentar e nutricional, conforme artigo $3^{\circ}$ da lei supracitada, constitui-se no acesso regular e permanente à alimentação saudável, suficiente e sustentável, que não comprometa o acesso a outras necessidades fundamentais.

Para Ramos (2015), a agricultura familiar, a feira livre e a segurança alimentar são eixos interligados e "as feiras podem constituir-se em um canal de reaproximação entre produtor e consumidor, associadas à redescoberta de um sistema alimentar influenciado e enfraquecido" (RAMOS, 2015, p. 03).

A feira não abrange apenas a agricultura familiar, mas também os consumidores e a população urbana como um todo, gerando receitas, dinamizando os municípios, criando e colocando em circulação recursos que alimentam a população urbana, contribuindo para a soberania alimentar, beneficiando agricultores, comércio e consumidores (RIBEIRO, 2007).

Godoy e Anjos (2007) ressaltaram o papel que as feiras vêm desempenhando na consolidação econômica e social, especialmente da agricultura familiar sob o ponto de vista do feirante, representando também um espaço público, socioeconômico e cultural, extremamente dinâmico e diversificado sob o ponto de vista do consumidor.

Ao estudar as feiras-livres do Jequitinhonha, em Minas Gerais, Ribeiro (2007) aponta que seriam elas umas das instituições mais sólidas no território mineiro. Além disso, o autor constata que os agricultores feirantes são beneficiados porque vendem uma produção que não entraria em outros mercados, já que sua pauta produtiva é muito associada à cultura alimentar local.

A dinamização da economia local pelo poder público - nesse caso, através das feiras - deve buscar a sustentabilidade e a essência das características locais. Estratégias de desenvolvimento nessa direção podem valorizar o lugar, fomentando a identidade cultural (CARPEGEANI; FILHO, 2009).

Há que se pensar em outros fatores capazes de inserir o agricultor familiar em mercados mais amplos através da cooperação e do associativismo. Pra et al. (2016) elucida a importância da 
organização coletiva:

A produção do excedente comercializável depende também da organização coletiva dos produtores mediante as associações comunitárias e o movimento sindical [...]. Esse processo de ação coletiva pela organização local representa o primeiro grau da construção social dos mercados e corresponde a relações de reciprocidade de tipo "compartilhamento de recursos" (tornando-os bens comuns ou públicos), seja a informação, o saber, o acesso a políticas etc. (PRA et al., 2016, p. 10-11).

A organização social promove o sentido de coletividade, além das trocas de saberes e do compartilhamento de técnicas e artefatos que podem contribuir com melhorias na produção, além de fortalecer a formação político-cidadã na luta por políticas públicas que venham garantir a manutenção desses espaços de comercialização da agricultura familiar e a criação de outros.

\section{Produção agropecuária de Cristina (MG)}

Conhecida pela presença da realeza portuguesa em suas terras pelos anos 1800 (IBGE, 2010) e pelas famosas fazendas, de importância histórico-cultural-patrimonial, Cristina segue a tradição cafeeira do sul de Minas, datada no início do século XIX e que até nossos dias continua a ser a atividade econômica predominante na região sul do estado (CRUZ, 2011). O município conquistou em 2014 e 2015 o prêmio Cup of Excellence Naturals, principal concurso internacional de café (CCCMG, 2016).

Com população de 10.210 habitantes, sua população rural gira em torno de $42 \%$ de sua população total (IBGE, 2010). O Censo Agropecuário 2006 mostrou que dos 20.268 hectares dos estabelecimentos agropecuários, aproximadamente $33 \%$ referem-se a lavouras, incluindo estabelecimentos familiares e não familiares.

Nos 827 estabelecimentos agropecuários do município, foram identificadas lavouras permanentes de café em $22 \%$ dos estabelecimentos e banana em 19\%. As lavouras temporárias de milho estão em $16 \%$ dos estabelecimentos, feijão em $8 \%$, de cana-de-açúcar em $1 \%$ e mandioca em 0,4\% (IBGE, 2006). Na pecuária, a presença de bovinos nos estabelecimentos agropecuários é predominante (69\%), seguido de equinos (38\%), galináceos $(33 \%)$, suínos $(18 \%)$ e muares $(15 \%)$. Foram identificados ainda outras aves $(8 \%)$, ovinos $(1 \%)$, caprinos $(0,8 \%)$ e asininos $(0,2 \%)$ (IBGE, 2006). 
Os estabelecimentos agropecuários com agricultura familiar correspondem a $86 \%$ do total de estabelecimentos e abrangem $47 \%$ das terras, ocupando $63 \%$ de pessoas na agricultura familiar. Os dados secundários mostram a importância da agricultura familiar para a economia do município. Reforça ainda os argumentos de Wanderley (2001) quanto a uma nova percepção positiva sobre o meio rural como portador de "soluções" para emprego, qualidade de vida e aprofundamento das relações sociais.

A realidade apresentada pelos dados estatísticos corrobora as afirmações de Wanderley (2001) quanto aos pequenos municípios como parte integrante do mundo rural. Parte significativa da população brasileira vive nas zonas rurais de pequenos municípios, de até 20 mil habitantes ou entre 20 e 50 mil habitantes. A autora coloca que a "pequena dimensão dos municípios e sua estreita dependência do mundo rural é um fato reconhecido no processo de urbanização nacional em seu conjunto" (WANDERLEY, 2001, p. 36). A autora indica a importância de reflexão sobre as particularidades da urbanização nos pequenos municípios e as relações campo-cidade, ainda pouco desenvolvidas (WANDERLEY, 2001).

A agropecuária e a agricultura familiar estão presentes e cumprem papel fundamental na realidade socioeconômica de Cristina, mas seu fortalecimento demanda outras estratégias para diversificar a produção e aumentar os rendimentos dessa categoria, de modo a garantir a autonomia econômica das famílias agricultoras.

\section{Diversidade produtiva da agricultura familiar de Cristina: concentração cafeeira}

As informações compartilhadas pela Emater quanto aos principais produtos cultivados pela agricultura familiar estão alinhadas aos dados do Censo Agropecuário. O café e a banana são os principais cultivos, além do milho, utilizado para o tratamento dos animais, e do feijão e pomares para autoconsumo. Alguns agricultores fazem o beneficiamento da banana e outros entregam para atravessadores. Na pecuária, o leite é o principal produto gerador de renda, com presença ainda de galinhas, porcos e pequena produção de peixe para autoconsumo. O leite é comercializado para cooperativas que revendem para a indústria. Mas é o café que vem ganhando espaço entre os pequenos produtores já que o gado gera rendimentos de longo prazo e a banana tem rendimentos menores.

A realidade histórica do município vinculado ao café vem norteando a produção familiar. Os agricultores que trabalhavam nas grandes fazendas foram adquirindo pequenos espaços de terra e conseguindo mudas de café através de políticas públicas. Essa massa de trabalhadores rurais deixou 
de ser explorada e passou a participar do processo de produção e ganhos, através do apoio dos técnicos da Emater e de agentes da prefeitura. Cristina está avançando na produção de café de pequenos produtores e já surgem agricultores interessados em produzir café orgânico, sendo que alguns já fazem uso de técnicas agroecológicas, apesar de não possuir ainda nenhuma lavoura certificada.

A produção envolve o plantio, colheita, secagem, limpeza, torrefação, com destino para estocagem ou comercialização para atravessadores, cooperativas ou empresas. Há empresas que estabelecem relação de exploração na negociação do café dos pequenos produtores, o que reforça a necessidade de organização de modo a lhes garantir um mercado mais justo.

No mercado de café pesquisado por Campos e Valente (2010), construído no Alto do Paraíso, em Goiás, os agricultores decidiram produzir cafés especiais, com domínio da cadeia produtiva e com bases também na produção agroecológica, produzindo café orgânico, recuperando a história e as tradições. As autoras ressaltaram que

[...] por meio do desvelamento de valores - história, cultura e tradições - é possível estabelecer estratégia mais eficiente de busca de mercado, a partir da experiência revelada no trabalho concreto e na cultura dos produtores (CAMPOS; VALENTE, 2010, p. 23).

Os mercados justos estão relacionados às questões ambientais (produção sustentável, orgânica e agroecológica) e às relações de trabalho em regimes conforme a legislação trabalhista e condições salubres. Um dos mercados de café mais conhecidos é o Fair Trade e o sul de Minas Gerais foi uma das primeiras regiões da América Latina a fazer parte desse tipo de mercado (BARONE; FREDERICO, 2015).

As atividades da Emater de Cristina estão concentradas no café e têm convergido no sentido de fortalecer a categoria dos pequenos produtores. Há produtores que já fazem parte da Associação Fair Trade, juntamente com a Cooperativa de café de Carmo de Minas, formada por 50\% de agricultores familiares. Os técnicos precisam atender à chamada pública SAF Ater 10/2012, projeto do MDA, e cumprir as metas determinadas, realizando a supervisão, assessoria e físcalização. Os 29 produtores selecionados estão sendo agentes multiplicadores do conhecimento adquirido, se tornando unidades de referência (UR) na produção cafeeira em pequenas áreas.

Pelo perfil turístico do município, a Emater atua nas ações de incentivo ao turismo como o evento "Café com Música". Foi proposto o concurso de café dos pequenos produtores em 2016, que despertou sentimento de orgulho entre os produtores. Há intenção da Emater em realizar um roteiro turístico para conhecer a produção e experimentar o café dos pequenos produtores, fazendo do 
turismo local um meio de comercialização para o agricultor familiar cafeeiro. Acredita-se que essa possa ser uma das estratégias de valorização da produção do café da agricultura familiar de Cristina e fomento para o desenvolvimento rural de base territorial.

No entanto, deve existir um equilíbrio entre a vocação cafeeira e a diversificação da produção, prática importante tanto para as famílias agricultoras quanto para os consumidores. Como exemplo, temos os produtores de café de Manhuaçu (MG), retratados na pesquisa de Barbosa et al. (2016). Os autores perceberam que a produção de hortaliças nas propriedades produtoras de café gerou um incremento 50\% superior à renda da propriedade não diversificada. Tem havido um esforço por parte da Emater em retomar as hortas nas pequenas propriedades, processo dificultado pelo interesse das mulheres em trabalhar nas lavouras de café. Motivadas pelos ganhos no café, estão perdendo o interesse no cultivo da horta.

Apesar da concentração cafeeira, foram identificadas algumas agroindústrias de queijo, bananinha, cachaça e quitandas. Wanderley (2001) afirma que é a partir da agricultura e da agroindústria que novos polos dinâmicos do desenvolvimento regional estão sendo gestados no Nordeste, tentando ocupar "nichos de mercado" nacional e internacional, fazendo frente à crise dos setores tradicionais da agricultura. Explorar as vantagens comparativas das agroindústrias e de produtos regionalizados pode ser uma alternativa de geração de renda para a agricultura familiar do município.

Os técnicos entrevistados alegam ainda que há carência de pesquisas sobre a produção em regiões de montanhas. As investigações nessa área estão concentradas em Machado, Lavras e Viçosa, regiões com características de solo e geografia muito distintas da realidade do município. Reforça-se a importância da aproximação da universidade com as comunidades rurais e os agentes de desenvolvimento, de modo a fortalecer a extensão universitária como instrumento mantenedor do diálogo da universidade com a sociedade (FORPROEX, 2012).

A entrevista realizada com a agricultora participante da feira de Cristina - assunto a ser tratado em seção posterior - apresentou outras variedades nas pequenas propriedades. Além da banana, milho, feijão e frutas diversas (pomares) já apresentados pelos dados do Censo Agropecuário e pela Emater, abóbora, amendoim, mel e hortaliças completam o sistema de produção da família, que é, no geral, para consumo da casa e no trato das vacas.

As frutas são utilizadas para produção de doces e quitandas, às vezes vendidas na própria vizinhança. A agricultora aprendeu a técnica de conservação, congelando as poupas no freezer, o que lhe garante matéria-prima o ano todo. $\mathrm{O}$ armazenamento adequado das frutas durante a safra evita as perdas, já que as frutas podem ser congeladas (entre outras técnicas) para posterior utilização 
(MISHRA, 2007).

A agricultora informa que todos os moradores do bairro têm produção semelhante e que dificilmente precisa comprar suprimentos no comércio. O sistema de produção dessa família ratifica as alegações de Abramovay (1992) quando afirma que o que diferencia o agricultor familiar de um outro comerciante comum é que, caso o mercado não lhe seja adequado, a alimentação da sua família não estará comprometida.

Em síntese, a produção da agricultura familiar de Cristina baseia-se principalmente no café, leite, banana e milho, produtos geradores de renda, e feijão, pomar, galinhas, porcos, peixe, abóbora, amendoim, mel e hortaliças para autoconsumo, além da presença de alguns produtores de referência na agroindústria. A produção cafeeira é característica de Cristina e tradicional do Sul de Minas, mas há que se ter cuidado para a não dependência de uma única cultura como fonte de geração de renda para as famílias, o que pode torná-las vulneráveis às especulações de mercado.

\section{Mercados institucionais: participação da agricultura familiar de Cristina no PNAE}

Segundo informações dos técnicos da Emater, há apenas 06 agricultores familiares participando do PNAE e não há participação no PAA. O PNAE é considerado pelos entrevistados um programa menos burocrático. Além disso, a prefeitura possui controle sobre todo o processo de aquisição de alimentos da agricultura familiar para as escolas municipais, dando segurança às famílias de que irão receber o recurso. Os produtos vendidos no PNAE são: bananinha, verduras, queijo e leite.

A divulgação das informações sobre o PNAE ocorre pela Emater, que avisa as lideranças de bairro sobre o edital e marca um dia para todos os interessados irem à empresa para fazerem o projeto numa mesma data. O edital é entregue junto com a carta de reunião. É oferecido auxílio na documentação e no fechamento e assinatura do contrato. Já é do conhecimento da instituição sobre quem tem interesse e condições de cumprir a entrega estabelecida. A chamada pública é semestral e os técnicos da Emater afirmam que dá mais trabalho, mas é mais seguro para a família, pois evita os riscos da sazonalidade.

Esse apoio dado pela Emater é essencial, pois segundo Souza-Esquerdo e Bergamasco (2014), somente a abertura da chamada pública não garante a participação da agricultura familiar, havendo necessidade do trabalho de mobilização e vontade política de promoção e fortalecimento da agricultura familiar. 
Ainda assim, a chamada pública cumpre apenas os $30 \%$ de aquisição de produtos da agricultura familiar. O programa permite que a compra atinja 100\% do recurso suplementar do FNDE para aquisição de alimentos da categoria. O cumprimento do percentual mínimo é considerado pequeno haja vista a característica rural do município. Segundo os técnicos da Emater, aqueles que não participam do programa não querem usar o tempo lidando com papel, edital, reunião, burocracia, pois têm que deixar a lavoura e não acreditam no retorno financeiro.

A pouca participação das famílias no programa pode ser consequência das características culturais dos agricultores da região, não acostumados a trabalhar coletivamente. A ausência da mobilização e de práticas associativas foi discutida por Ferreira et al. (2009), que atribuíram ao tipo de colonização do sul de Minas a desconfiança quanto às formas de trabalho coletivo. Os autores perceberam que os agricultores, de maneira geral, desconfiavam dos benefícios das práticas associativistas e os casos de insucesso nessa prática são vistos como algo que tende a se perpetuar (FERREIRA et al., 2009).

Modificar padrões histórico-culturais não é tarefa fácil e requer grande esforço dos diversos agentes de desenvolvimento rural, incluindo o poder público e a universidade. A inserção nas comunidades, a presença frequente, a conquista da confiança e o trabalho incessante e prolongado, com o uso de metodologias adequadas, são alguns dos inúmeros caminhos para embutir nas comunidades rurais a formação associativa.

A aquisição de produtos da agricultura familiar só atinge a exigência mínima de $30 \%$ por causa da compra do leite, que possui maior valor de venda, resultado da mobilização de um agricultor que organizou um grupo de produtores para poder oferecer o item ao programa. Nota-se a importância da organização, da formação do grupo como comunidade, da organização coletiva para construção social dos mercados e comercialização da produção excedente (PRA et al., 2016). A organização social promove o sentimento de coletividade, além de fortalecer a conscientização para a luta por políticas públicas que garantam a manutenção e criação de programas e políticas para o desenvolvimento rural e para a agricultura familiar.

Sobre o incentivo à participação, no passado a prefeitura deu apoio no transporte dos alimentos entregues para o PNAE. Atualmente, prefere pagar mais (15\%), mas não oferecer o transporte. A logística dos alimentos é um gargalo geral para participação da agricultura familiar no programa em todas as regiões do Brasil e também um desafio para as unidades executoras, uma vez que a logística sempre foi uma vantagem dos atravessadores, grandes distribuidores e atacadistas (ROSSETTI; WINNIE; SILVA, 2016).

Marques et al. (2014) apontaram o transporte como um dos maiores entraves para os 
agricultores familiares de Araripe (Ceará) participarem do PNAE. Costa, Amorim Jr. e Silva (2015, p. 07) ressaltaram que a logística é um problema para as cooperativas e "em momento algum o programa prevê a remuneração dos custos com a logística de distribuição dos produtos, apenas estabelece os preços pagos pelos produtos".

O pagamento que a prefeitura de Cristina faz para o transporte é algo positivo se comparado à realidade de outras prefeituras país afora. Contudo, o financiamento do transporte pela prefeitura, em vez da disponibilização, restringe a participação àqueles que possuem carro. Segundo os técnicos da Emater, a dificuldade com o transporte é outra justificativa para agricultores não participarem do programa. Algumas famílias que moram longe acreditam que não compensa levar pouca produção e arcar com os custos do transporte.

Outra opção que poderia facilitar o transporte seria descentralizar os locais de recebimento, pois muitos alimentos saem da zona rural, vão para a sede municipal e retornam para as escolas da zona rural. Castro (2014) sugere que cada comunidade, ou comunidades rurais próximas, poderia ter um ponto de recebimento, facilitando a entrega dos alimentos pelos agricultores e superando um gargalo importante do programa. Segundo a autora, seria a

regionalização das entregas, ou seja, o produtor realiza a entrega nas escolas que estiverem mais próximas a ele, evitando dessa forma grandes deslocamentos e, consequentemente, aumento dos custos (CASTRO, 2014, p. 61).

Percebe-se que o fornecimento do transporte pela prefeitura ou pelo estado possibilitaria a ampliação da participação dos agricultores no programa, embora poucas prefeituras se disponham ou têm condições de fornecer o frete (CASTRO, 2014).

Outra característica do município que dificulta a ampliação da compra da agricultura familiar para o PNAE é a presença da horta na escola municipal, cuidada por um funcionário da prefeitura contratado para essa função. A horta abastece a escola que, portanto, não possui grande demanda de hortaliças. A horta escolar é importante quando usada também para fins didáticos, mas não pode anular a execução do PNAE. A gestão municipal de Cristina vem tentando conciliar os alimentos adquiridos na horta e no PNAE.

O PNAE é um programa importante para a agricultura familiar de Cristina, diferente do PAA, que não se mostrou exequível. No entanto, o programa tem potencial para ampliar a adesão já que existem 712 estabelecimentos agropecuários da agricultura familiar; produção, ainda que pequena, de café, banana, feijão, milho, frutas diversas, abóbora, amendoim, mel, hortaliças ovos, leite, queijo, bananinha e quitandas e a possibilidade de aquisição de $100 \%$ de produtos da agricultura familiar, 
com dificuldades de atingir os 30\% exigidos pela legislação. Incentivar a diversificação produtiva, garantir transporte gratuito para a coleta dos produtos e mobilizar os agricultores quanto aos benefícios do programa são os grandes desafios de Cristina para ampliar a participação da agricultura familiar no PNAE.

\section{A feira de Cristina (MG)}

As feiras livres são importantes canais de comercialização que raramente recebem apoio de políticas públicas específicas. Quando recebem, são marcados pelo caráter produtivista e mercadológico da atividade, deixando de lado seu caráter cultural e sociológico. Elas são um importante espaço de comercialização dos produtos da agricultura familiar, mas também um importante espaço de socialização, identidade regional e cultural e de articulação política.

Nas feiras há movimentação de produtos, pessoas, informações e cultura, numa dinâmica muito peculiar, que se misturam com a paisagem local. A importância da feira também se dá na oportunidade de abastecimento de produtos de características locais, o que serve como um impulsionador da agricultura familiar e o desenvolvimento rural em bases sustentáveis.

Diante da importância, não só econômica, das feiras livres, pretendeu fazer uma análise sobre a dinâmica de funcionamento da feira de Cristina, que possa subsidiar as ações do poder público local e ações coletivas dos feirantes no sentido de fortalecer esse espaço.

A feira existe há quase 40 anos e começou com a intenção de fazê-la como canal de comercialização para os agricultores, sendo que no passado contou com 38 barracas. É regulamentada pela prefeitura e funciona ao lado da estação rodoviária, todas às sextas-feiras, das $06 \mathrm{~h} 30$ às $12 \mathrm{~h} 30$. Sua periocidade semanal e modalidade ao ar livre adequa-se à definição de feira livre proposta por Mascarenhas e Dolzani (2008).

Entretanto, a realidade atual da feira não é mais a mesma. No período da coleta de dados, foram contabilizadas 10 barracas que compõem a feira e apenas uma delas - a barraca de doces e quitandas - é de família agricultora. Há uma barraca grande de hortifrutigranjeiros com frutas advindas do Ceasa e de produtos de diversos agricultores de Cristina, sendo, portanto, de atravessadores. Essa barraca é a de maior movimento, segundo observação e dados de entrevista, já que as verduras não são vendidas em outros mercados da cidade.

Para Abramovay (1999), o atravessador (ou bodegueiro, dependendo da região) é o comerciante que se torna o destinatário natural dos resultados do trabalho agrícola dos produtores 
rurais, que depois é revendido em redes de supermercados, no Ceasa e até mesmo em feiras livres. Essa relação entre produtor e atravessador dificulta o crescimento econômico do setor agrícola e o desenvolvimento local de bairros, municípios ou regiões. Para Braudel (2009), a sobrevivência das feiras deve-se, entre outros fatores, à venda sem intermediários, em que prevalece a relação de troca transparente e o frescor dos gêneros perecíveis trazidos dos campos que a circundam. A presença do intermediário rompe a rede de confiança, característica das feiras livres.

As outras barracas que compõem a feira são a barraca de pastel e cinco barracas de roupas, as quais descaracterizam a feira como espaço de distribuição local de gêneros alimentícios (MASCARENHAS; DOLZANI, 2008). Há outras duas barracas - de caldo de cana e churros - que recentemente passaram a ocupar esse espaço todos os dias.

Além disso, uma vez por mês está acontecendo a barraca de artesanato, das artesãs dos bairros rurais, de iniciativa e apoio da Emater, na tentativa de fomentar a feira como um espaço turístico da cidade. O público que frequenta a feira são os moradores do município, visitantes - que incluem ex-moradores de Cristina, que nasceram no município e retornam para passear e rever a família - e turistas. $\mathrm{O}$ fortalecimento da feira através do turismo vem atender às afirmações de Carpegeani e Filho (2009) sobre a dinamização da feira pelo poder público pela via da valorização do lugar, fomentando a identidade cultural. A presença do turista pode ser explicada pela imagem simbólica em relação à natureza e mundo rural que revelam algumas feiras (AGUILAR, 2004), simbolismo que desperta sedução como apelo turístico de identidade local.

Para participar da feira e ter direito ao ponto, o feirante precisa pagar semanalmente $\mathrm{R} \$ 16,50$ (dezesseis reais e cinquenta centavos). A estrutura das barracas é do feirante e cada um é responsável pelo transporte, montagem e desmontagem. No início do funcionamento da feira a prefeitura disponibilizava transporte, o que ocorreu por 04 ou 05 meses, mas não foi tratado como ação pública. Diante da falta desse apoio, o grupo de feirantes passou a alugar carro particular e arcar com os custos, o que inviabilizou a permanência deles, fazendo com que desistissem.

Dentre os fatores apontados por Ribeiro et al. (2003) que poderiam servir de base para o direcionamento de políticas públicas ao segmento das feiras livres locais, o apoio ao transporte dos feirantes e de seus produtos é fator imprescindível para ampliar o número de agricultores beneficiados pela comercialização nesses espaços urbanos.

Além do deslocamento deles próprios, o feirante padece com o peso dos alimentos e produtos que serão levados para venda na feira. Em muitos municípios do Vale do Jequitinhonha, as prefeituras estabeleceram rotas de deslocamento de ônibus ou caminhões para o transporte gratuito dos feirantes (RIBEIRO, 2007), o que promove a superação na dificuldade com o deslocamento. 
Segundo dados de entrevista, alguns agricultores do município vendem seus produtos em quitandas presentes em 03 pontos diferentes da cidade, onde são ofertados legumes e frutas. Os proprietários das quitandas são produtores e comercializam, além de sua produção, a produção de agricultores do município. As quitandas não foram investigadas nesta pesquisa, mas surgiram como dado da entrevista com a feirante.

Embora o local seja apropriado, com banheiro e água disponível para uso dos feirantes, a feira foi enfraquecendo ao longo dos anos. Sem o apoio necessário para a sua consolidação, a feira livre de Cristina se descaracterizou, transformando-se em um espaço ocupado em grande parte por intermediadores e não pela venda direta do produtor ao consumidor final.

Entretanto, com todas essas adversidades, ainda há uma agricultora que permanece na feira toda semana, há dezessete anos. A feirante aprendeu sobre a produção de doces e quitandas com a Emater e frequenta, além desse espaço, a Feira de São Lourenço, eventos e convites de hotéis da cidade. A geração de renda para as mulheres a partir do processamento do que se planta e colhe é também uma possibilidade de permanência no campo (SILVA; NASCIMENTO; GORES, 2015).

Ressalta-se que apesar da hibridização cultural no meio rural, muitos costumes ainda permanecem, incorporados em uma nova lógica, como as produções de queijos e geleias, feitas outrora para consumo familiar e hoje frequentemente produzidos para a venda, mantendo-se o costume e mudando a lógica da produção (OLIVEIRA, 2014).

A produção dos doces e quitandas a partir do processamento e conservação da produção familiar, além de incrementar a renda familiar, mantém os costumes e o aproveitamento de alimentos com características do lugar. Apoia-se ainda nas considerações de Ribeiro et al. (2003) sobre a busca de mercados específicos, baseados na agregação de valor aos bens agrícolas, cuja produção esteja fundamentada em diferenciais qualitativos de natureza social, ambiental ou cultural, consolidados por uma demanda segmentada, composta de consumidores dispostos a pagar um preço também diferenciado.

Ao iniciar sua participação, ela ganhou a barraca da prefeitura, não tendo havido necessidade de maiores investimentos. O acompanhamento das políticas de fomento a esse tipo de atividade é fundamental para a consolidação desses espaços. Como exemplo dessas políticas temos o Programa de Apoio às Feiras Livres, do governo estadual de Minas Gerais, que fornece o "kit feira" às cidades que promovem feiras livres com a oferta da produção vinda da agricultura familiar. Cada kit é composto por 10 barracas, 20 jalecos e 60 caixas plásticas (MINAS GERAIS, 2017).

Atualmente, a filha caçula ajuda na produção das quitandas e o marido realiza o transporte dela e dos produtos, em um esforço familiar e coletivo que fortalece a continuidade da atividade. 
Ressalta-se que a feirante é moradora de um bairro rural próximo à cidade, situação que favorece o acesso e a participação na feira, o que reforça a necessidade do apoio do poder público no transporte dos feirantes e de seus produtos (RIBEIRO, 2003).

A renda da feira corresponde, para a sua família, mais da metade da sua renda pessoal. O recurso é usado na compra de produtos de limpeza e higiene pessoal para a casa e ingredientes extras necessários para a produção das quitandas e que não são produzidos na unidade familiar. A renda da feira foi também o que ajudou a família a comprar a terra em que vive e ajudar nos estudos dos filhos. A feira é reconhecidamente um espaço importante de geração de renda para os agricultores (ANJOS et al., 2005;), produzindo receitas que dinamizam os municípios, beneficiando agricultores, comércio urbano e consumidores (RIBEIRO et al., 2003).

A feira livre de Cristina é um espaço que precisa ser repensado e subsidiado para cumprir seus objetivos primários. A ausência de apoio do poder público, no passado, principalmente no que se refere ao transporte, parece ser a grande desarticuladora desse espaço. Atualmente, a forte presença de atravessadores e de comércio de roupas descaracteriza a feira como espaço de comercialização de gêneros alimentícios locais, de trocas comerciais, sociais e culturais.

Entretanto, a permanência de uma agricultora mostrou que apesar da descaracterização desse espaço, ele ainda se apresenta relevante como canal de comercialização e geração de renda. A feira apareceu como principal fonte de renda para essa família e por meio de incentivos dos agentes de desenvolvimento local, seus benefícios poderão ser ampliados para outras famílias. O acesso a programas específicos para essa atividade, como a aquisição do kit feira e o fortalecimento pela via do turismo, podem recuperar esse espaço criado e destinado aos agricultores e agricultoras do município.

\section{Considerações finais}

A questão que orientou este trabalho referiu-se à diversidade produtiva e à inclusão em mercados que garantam a comercialização dessa produção, a soberania alimentar e a reprodução dos modos de vida das famílias agricultoras. Nosso objetivo foi conhecer a diversidade produtiva e a participação nos mercados locais e institucionais da agricultura familiar do município.

O conjunto dos dados analisados mostrou a pouca atuação do poder público na construção de políticas e ações que dinamizem a agricultura familiar e promovam o desenvolvimento rural. Uma possível explicação para isso é a existência no meio rural de uma grande contradição: se de um lado 
tem-se a revalorização do rural e a viabilização de políticas públicas que buscam dinamizar as sociedades rurais, por outro lado há uma força contrária, baseada num modelo de desenvolvimento economicista, que prioriza a produção de commodities em sistemas monocultores.

No caso de Cristina, a produção de café demanda aprofundamentos de pesquisa para compreender os benefícios e os entraves para o desenvolvimento rural. Percebe-se um interesse das entidades regionais e do poder público em fomentar essa produção, inclusive da perspectiva dos eventos culturais e do turismo. Faz-se fundamental pensar em estratégias organizativas das famílias para superar a dependência da monocultura. Fomentar a criação de associações rurais, construídas por laços de compadrio e vizinhança entre as famílias, que sirvam de base para o fortalecimento das ações coletivas, para que as comunidades, alicerçadas nas suas identidades, criem caminhos próprios para superar situações adversas e assim, associar-se, mais do que em função de mera formalidade, tornando-se sinônimo de "juntar-se" em torno de algo comum e solidário.

Para tanto, atenta-se para o papel da universidade como mediadora e formadora nas práticas colaborativas e solidárias junto às comunidades, não limitando suas discussões nos espaços acadêmicos e fazendo cumprir o seu papel de ensino, pesquisa e extensão. Em tempos de desmantelamento do Estado, de perdas de direitos garantidos, de fragilização da democracia, o fortalecimento das organizações sociais no campo parece ser a única saída para minimizar os desmanches iminentes. Os cortes em direitos e programas sociais, anúncios de privatizações e redução dos programas para a agricultura familiar podem impelir o êxodo rural, a violência no campo, a vulnerabilidade social e o empobrecimento do meio rural, além de colocar em risco a segurança alimentar de toda a sociedade brasileira (MATTOS, 2017).

A despeito da atuação de outros agentes do poder público, a assistência da Emater tanto na participação no PNAE quanto na produção cafeeira dos pequenos agricultores tem mostrado que o apoio dos agentes de desenvolvimento é fundamental para acessar mercados ainda estranhos aos agricultores.

A feira livre descaracterizou-se como espaço de comercialização da agricultura familiar, objetivo definido quando esta foi inaugurada. Contudo, ainda que com somente uma família agricultora participante, a feira pode ser considerada um espaço importante de fonte de renda e de manutenção sociocultural da categoria. Fica ao encargo dos agentes de desenvolvimento local criar mecanismos de incentivo para participação da agricultura familiar na feira do município. O espaço poderia ser estimulado com ações culturais provenientes da própria comunidade rural, retomando-o como canal de comercialização da produção e de trocas culturais.

Percebeu-se que além do PNAE e da feira, a presença das quitandas para a comercialização 
de legumes e frutas é marcante. Investigações para conhecer a lógica desses estabelecimentos, seu sistema de compra e venda e o público frequentador ajudarão a ampliar a compreensão da produção e comercialização da agricultura familiar no município.

Reforça-se a importância de formulação de políticas públicas municipais adequadas à realidade e peculiaridades locais. Mais uma vez evoca-se a universidade para ajudar a pensar instrumentos de apoio aos gestores de pequenos municípios que forneçam informações estruturadas da realidade local para a elaboração do planejamento municipal.

Os limites desta pesquisa ficaram por conta do público investigado: apenas os técnicos da Emater e uma única agricultora presente na feira não são suficientes para a compreensão ampla da agricultura familiar do município. As informações apresentadas pela agricultora mostram que a realidade das famílias em termos de produção, ainda que para autoconsumo, é mais diversa do que a conhecida pela Emater e apresentada pelos dados do Censo Agropecuário.

Para aprofundar a percepção sobre a realidade da agricultura familiar de Cristina, faz-se fundamental visitar as comunidades e as propriedades dos agricultores, estabelecer diálogos com as associações, com as lideranças locais e com as diversas famílias agricultoras do município, compreender as razões que motivam e/ou desmobilizam a participação em determinados mercados, além de conhecer outras estratégias de geração de renda.

\section{Referências}

ABRAMOVAY, R. Agricultura familiar e desenvolvimento territorial. Revista da Associação Brasileira de Reforma Agrária, v. 28, n. 1, 1999.

ABRAMOVAY, R. Paradigmas do capitalismo agrário em questão. São Paulo: Hucitec, 1992.

AGUILAR, A. Feira livre: o consumo cultural na prática. Diário Popular, Pelotas, p. 7, 28 mar. 2004.

ANGULO, J. L. G. Mercado local, produção familiar e desenvolvimento: estudo de caso da feira de Turmalina, Vale do Jequitinhonha, MG. Organizações Rurais e Agroindustriais, v. 5, n. 2, p. 2003.

ANJOS, F. S.; GODOY, W. I.; CALDAS, N. V. As feiras-livres de Pelotas sob o império da globalização: perspectivas e tendências. Pelotas: Editora e Gráfica Universitária, 2005.

BACCARIN, J. G.; TRICHES, R. M.; TEO, C. R. P. A.; SILVA, D. B. P. Indicadores de Avaliação das Compras da Agricultura Familiar para Alimentação Escolar no Paraná, Santa Catarina e São Paulo. Revista de Economia e Sociologia Rural, v. 55, n. 1, p. 103-122, 2017. Disponível em: <https://bit.ly/2HlGNq9>. Acesso em: 22 dez. 2017. 
BARBOSA, P. J. F.; CASAROTTO, E. L.; MACHADO, R. R.; ALMEIDA, V. L.; VITORINO FILHO; V. A. A importância da diversificação agrícola como complemento na renda familiar na região de Manhuaçu - MG. Revista CCEI - URCAMP, v. 20, n. 35, p. 1-11, 2016. Disponível em: <https://bit.ly/2IWMwA1>. Acesso em: 23 dez. 2017.

BARONE, M.; FREDERICO, S. La ciudad brasileña del Comercio Justo: una experiencia pionera en Poços de Caldas. Revista Eutopía, n. 7, p. 59-73, 2015. Disponível em: <http://revistas.flacsoandes.edu.ec/eutopia/article/view/1632/1327>. Acesso em: 22 dez. 2017.

BRASIL. Lei $\mathbf{n}^{\mathbf{0}}$ 11.947, de 16 de junho de 2009. Dispõe sobre o atendimento da alimentação escolar e do Programa Dinheiro Direto na Escola aos alunos da Educação Básica. Disponível em: <https://bit.ly/1kpWU3P>. Acesso em: 11 jan. 2018.

BRAUDEL, F. O jogo das trocas. Civilização material, economia e capitalismo: século XV-XVIII. São Paulo: Martins Fontes, 2009.

BUAINAIN, A. M.; SOUZA FILHO, H. M. Agricultura familiar, agroecologia e desenvolvimento sustentável: questões para debate. Brasília: IICA, 2006.

CAMPOS, J. I.; VALENTE, A. L. E. F. A construção do mercado para o café em Alto Paraíso de Goiás. Revista de Economia e Sociologia Rural, v. 48, n. 1, p. 23-40, 2010. Disponível em: <https://bit.ly/2H1vct9>. Acesso em: 23 dez. 2017.

CARNEIRO, M. J. Política pública e agricultura familiar: uma leitura do Pronaf. Estudos Sociedade e Agricultura, n. 8, p. 70-82, 1997. Disponível em: 〈https://bit.ly/2JKbfbU〉. Acesso em: 03 set. 2017.

CARPEGEANI, C. B. F.; FILHO, C. B. R. Caminho das tropas: a importância da preservação histórica e cultural como meio de preservação ambiental no Vale do Paraíba. Revista Ciências Humanas, v. 1, n. 1, p. 01-20, 2009. Disponível em: <http://revistas.unitau.br/ojs2.2/index.php/humanas/article/view/571/534>. Acesso em: 03 set. 2017.

CASTRO, T. P. A contribuição do Programa Nacional de Alimentação Escolar (PNAE) para a reprodução camponesa: um estudo de caso da Associação Comunitária Rural Alvorada (Acra). 2014. Dissertação (Mestrado em Geografia Humana) - Departamento de Geografia, Faculdade de Filosofia, Letras e Ciências Humanas, Universidade de São Paulo, São Paulo. Disponível em: <https://bit.ly/2JJiBwm>. Acesso em: 20 dez. 2017.

CENTRO DO COMÉRCIO DE CAFÉ DO ESTADO DE MINAS GERAIS (CCCMG). Conheça o café de Cristina (MG) que ganhou prêmios internacionais. 28 ago. 2016. Disponível em: <https://bit.ly/2JN9oTZ>. Acesso: em 31 dez. 2017.

COSTA, B. A. L.; AMORIM JR., P. C. G.; SILVA, M. G. As cooperativas de agricultura familiar e o mercado de compras governamentais em Minas Gerais. Revista de Economia e Sociologia Rural, v. 53, n. 1, p. 109-125, 2015. Disponível em: 〈https://bit.ly/2GXSvUI〉. Acesso em: 19 dez. 2017. 
CRUZ, E. C. F. Pomares e jardins das fazendas de café: Serra da Bocaina no Vale do Paraíba e Serra da Mantiqueira no Sul de Minas. Revista Labor \& Engenho, v. 5, n. 4, p. 89-105, 2011. Disponível em: <https://bit.ly/2IWsfL0>. Acesso em: 31 dez. 2017.

DURHAM, E. R. A caminho da cidade: a vida rural e a migração para São Paulo. 3. ed. São Paulo: Perspectiva, 1984.

FERRARI, D. L. Cadeias agroalimentares curtas: a construção social de mercados de qualidade pelos agricultores familiares em Santa Catarina. Tese (Doutorado em Desenvolvimento Rural). Faculdade de Ciências Econômicas. Universidade Federal do Rio Grande do Sul, Porto Alegre, 2011. Disponível em: <http://www.lume.ufrgs.br/handle/10183/49829>. Acesso em: 02 set. 2017.

FERREIRA, P. A.; PEREIRA, J. R.; ALENCAR, E.; SANTANA, A. C. Estado e agricultores familiares: uma análise interpretativa sobre o desenvolvimento rural no Sul de Minas Gerais. Revista de Economia e Sociologia Rural, v. 47, n. 3, p. 767-792, 2009. Disponível em: <https://bit.ly/2IXya2h>. Acesso em: 29 dez. 2017.

FÓRUM DE PRÓ-REITORES DAS INSTITUIÇÕES PÚBLICAS DE EDUCAÇÃO SUPERIOR BRASILEIRAS (FORPROEX). Política Nacional de Extensão Universitária. Manaus: 2012.

FUNDO NACIONAL DE DESENVOLVIMENTO DA EDUCAÇÃO (FNDE). PNAE. Sobre o PNAE. Disponível em: <https://bit.ly/2GXBxd7>. Acesso em: 22 dez. 2017.

FUNDO NACIONAL DE DESENVOLVIMENTO DA EDUCAÇÃO (FNDE). Liberação de recursos. FNDE repassa R \$ 406 milhões para alimentação e transporte escolar. FNDE, 05 jun. 2017. Disponível em: <https://bit.ly/2IWQhW9>. Acesso em: 25 fev. 2018.

GODOY, W.; ANJOS, F. S. A importância das feiras livres ecológicas: um espaço de trocas e saberes da economia local. In: II CONGRESSO BRASILEIRO DE AGROECOLOGIA, n. 2, 2007, Cruz Alta, Rev. Bras. Agroecologia, 2007, p. 364-368. Disponível em: http://revistas.abaagroecologia.org.br/index.php/cad/article/view/1943>. Acesso em: 03 set. 2017.

GRISA, C.; SCHNEIDER, S. Três gerações de políticas públicas para a agricultura familiar e formas de interação entre sociedade e estado no Brasil. Revista de Economia e Sociologia Rural, v. 52, supl.1, p. 125-146, 2014. Disponível em: <http://www.scielo.br/pdf/resr/v52s1/a07v52s1.pdf〉. Acesso em: 20 dez. 2017.

HÖFling, E. M. Estado e Políticas (Públicas) Sociais. Cadernos Cedes, n. 55, p. 30-41, 2001. Disponível em: <http://www.scielo.br/pdf/ccedes/v21n55/5539.pdf>. Acesso em: 26 fev. 2018.

INSTITUTO BRASILEIRO DE GEOGRAFIA E ESTATÍSTICA (IBGE). Censo demográfico 2010. Cristina - MG. Acesso em: 12 jul. 2017.

INSTITUTO BRASILEIRO DE GEOGRAFIA E ESTATÍSTICA (IBGE). Censo agropecuário 2006. Acesso em: ago. 2016.

MARQUES, A. A.; FERNANDES, M. G. M.; LEITE, I. N.; VIANA, R. T., GONÇALVES, M. C.; CARVALHO, A. T. Reflexões de agricultores familiares sobre a dinâmica de fornecimento de seus produtos para a alimentação escolar: o caso de Araripe, Ceará. Revista Saúde e Sociedade, v. 23, n. 
4, p. 1329-1341, 2014. Disponível em: <https://bit.ly/2Ho6Pch>. Acesso em: 19 dez. 2017.

MASCARENHAS, G.; DOLZANI, M. C. S. Feira livre: territorialidade popular e cultura na metrópole contemporânea. Revista Eletrônica Ateliê Geográfico, v. 2, n. 4, p. 72-87, 2008. Disponível em: <https://bit.ly/2JNqlxq>. Acesso em: 29 ago. 2017.

MATTOS, L. M. Austeridade fiscal e desestruturação das políticas públicas voltadas à agricultura familiar brasileira. Friedrich-Ebert-Stiftung (FES). Análise no 39, novembro de 2017. Disponível em: <http://library.fes.de/pdf-files/bueros/brasilien/13933.pdf〉. Acesso em: 22 fev. 2018.

MEDEIROS, L. S. Sem-terra, assentados, agricultores familiares: considerações sobre os conflitos sociais e as formas de organização dos trabalhadores rurais brasileiros. In: GIARRACCA, N. (Org.). ¿Una nueva ruralidad em America Latina? Buenos Aires: Clacso, 2001. p. 107-133. Disponível em: <https://bit.ly/2IW763p>. Acesso em: 22 fev. 2018.

MISHRA, G. V. K. Postharvest handling and treatments of fruits and vegetables. In: RAHMAN, M. S. (Ed.). Handbook of food preservation. Boca Raton: CRC, 2007. Capítulo 1, p. 49-72.

MINAS GERAIS. Apoio a feiras livres da agricultura familiar "Aqui tem feira". Minas Gerais, 14 nov. 2017. Disponível em: 〈https://bit.ly/2qyqX1T>. Acesso em: 27 fev. 2018.

MORAES, M. D. C. De camponês a agricultor familiar: imagens do campesinato como identidades da ordem da razão. Raízes, v. 17, p. 121-134, jun. 1998. Disponível em: <http://www.ufcg.edu.br/ raizes/artigos/Artigo_136.pdf>. Acesso em: 22 fev. 1998.

OLIVEIRA, E. Agricultura familiar e sua identidade cultural no espaço rural. Revista Ciências Humanas, v. 7, n. 2, p. 173-188, 2014. Disponível em: 〈https://bit.ly/2Hoe5Fb>. Acesso em: 03 set. 2017.

PAULA, A. M.; GÓMES, J. R. M.; TRACZ, C. A. M. Novo ciclo neoliberal no Brasil: desmontando as políticas públicas para a agricultura camponesa. Revista Pegada, v. 18, n. 1, 2017. Disponível em: <https://bit.ly/2qtNXye>. Acesso em: 22 fev. 2018.

PRA, M.; SABOURIN, E.; PETERSEN, P.; SILVEIRA, L. Lógicas e estratégias de comercialização na agricultura familiar do Agreste da Paraíba. Estudos Sociedade e Agricultura, v. 24, n. 1, p. 5-27, 2016. Disponível em: <https://bit.ly/2vkpb9E>. Acesso em: 19 dez. 2017.

RAMOS, C. I. Frutas, legumes e verduras nas feiras livres de Pelotas e sua contribuição na segurança alimentar e nutricional. 2015. Dissertação (Programa de Pós-Graduação em Nutrição e Alimentos). Faculdade de Nutrição. Universidade Federal de Pelotas, Pelotas. Disponível em: <https://bit.ly/2IXHPpz>. Acesso em: 24 dez. 2017.

RIBEIRO, A. L. P.; CERATTI, S.; BROCH, D. T. Programa Nacional de Alimentação Escolar (PNAE) e a participação da agricultura familiar em municípios do Rio Grande do Sul. Revista Gestão e Desenvolvimento em Contexto, v. 1, n. 1, p. 36-49, 2013. Disponível em: <https://bit.ly/2IY0WQt>. Acesso em: 21 dez. 2017.

RIBEIRO, E. M.; ANGUlO, J. L. G.; NORONHA, A. B.; CASTRO, B. S.; GALIZONI, F. M.; CALIXO, J. S.; SILVESTRE, L. H. A feira e o trabalho rural no Alto Jequitinhonha: um estudo de 
caso em Turmalina, Minas Gerais. Unimontes Científica, v. 5, n. 1, p. 53-65, 2003. Disponível em: <http://www.ruc.unimontes.br/index.php/unicientifica/article/view/53/47>. Acesso em: 20 dez. 2017.

RIBEIRO, E. M. (Coord). Feiras do Jequitinhonha: mercados, cultura e trabalho de famílias rurais no semi-árido de Minas Gerais. Fortaleza: Banco do Nordeste do Brasil, 2007.

ROSSETTI, F. X.; WINNIE, L. W. Y.; SILVA, M. V. O Programa Nacional de Alimentação Escolar (PNAE) e o desafio da aquisição de alimentos regionais saudáveis. Revista Segurança Alimentar e Nutricional, v. 23, n. 2, p. 912-923, 2016. Disponível em: 〈https://bit.ly/2Hndm75>. Acesso em: 20 dez. 2017.

SCHNEIDER, S.; FERRARI, D. L. Cadeias curtas, cooperação e produtos de qualidade na agricultura familiar: o processo de relocalização da produção agroalimentar em Santa Catarina. Organizações Rurais \& Agroindustriais, v. 17, n. 1, p. 56-71, 2015. Disponível em: <http://revista.dae.ufla.br/index.php/ora/article/view/949/0>. Acesso em: 19 dez. 2017.

SCHNEIDER, S. Situando o desenvolvimento rural no Brasil: o contexto e as questões em debate. Revista de Economia Política, v. 30, n. 3, p. 511-531, 2010. Disponível em: <http://www.scielo.br/pdf/rep/v30n3/a09v30n3.pdf>. Acesso em: 19 dez. 2017.

SCHNEIDER, S. Ciências sociais, ruralidade e territórios: em busca de novas referências para pensar o desenvolvimento. Campo-Território: Revista de Geografia Agrária, v. 4, n. 7, p. 24-62, fev. 2009. Disponível em: <https://bit.ly/2H0JGO0>. Acesso em: 22 fev. 2018.

SILVA, A. T. B.; NASCIMENTO, R. S.; GORES, J. Agroecologia, relações produtivas e de gênero na agricultura familiar: o estudo de caso da Associação de Produtores Agroecológicos Sementes do Futuro de Atalanta - SC. Ágora, v. 17, n. 02, p. 131-143, 2015. Disponível em: <https://online.unisc.br/seer/index.php/agora/article/view/6675/4843>. Acesso em: 27 fev. 2018.

SOUZA, C. Políticas Públicas: uma revisão de literatura. Sociologias, n. 16, p. 20-45, 2006. Disponível em: 〈http://www.scielo.br/pdf/soc/n16/a03n16>. Acesso em: 25 fev. 2018.

SOUZA-ESQUERDO, V. F.; BERGAMASCO, S. M. P. P. Análise sobre o acesso aos programas de políticas públicas da agricultura familiar nos municípios do circuito das frutas (SP). Revista de Economia e Sociologia Rural, v. 52, supl. 1, p. 205-222, 2014. Disponível em: <https://bit.ly/2vkXopu>. Acesso em: $21 \mathrm{dez} .2017$.

WANDERLEY, M. N. B. O mundo rural como um espaço de vida - Reflexões sobre a propriedade da terra, agricultura familiar e ruralidade. Porto Alegre: Editora UFRGS, 2009.

WANDERLEY, M. N. B. A ruralidade no Brasil moderno. Por um pacto social pelo desenvolvimento rural. In.: GIARRACCA, N. ¿Una nueva ruralidad en América Latina? Buenos Aires: Clacso, 2001. Disponível em: <https://bit.ly/2bsp6X7>. Acesso em: 20 fev. 2018.

Artigo recebido em 11/01/2018. Aceito para publicação em 01/03/2018. 